\title{
Serum Progesterone as an Admission Prognostic Marker in Male Traumatic Brain Injury Patients
}

\author{
Arundhati Dasgupta $^{\mathrm{a}, \mathrm{b}}$, Dipti Sarma ${ }^{\mathrm{a}}$, Uma Kaimal Saikia ${ }^{\mathrm{a}}$
}

\begin{abstract}
Background: In this prospective study, we analyzed data in men with moderate traumatic brain injury, to find whether higher levels of serum progesterone at admission are associated with better prognosis.
\end{abstract}

Methods: One hundred male patients of traumatic brain injury, with a postresuscitation Glasgow Coma Scale score between 4 to 12 were enrolled and serum for progesterone collected at admission. Outcome was assessed 30 days postinjury according to Glasgow Outcome Scale (GOS) and Functional Independence Measure (FIM) score.

Results: The mean progesterone level in the group with GOS $\leq 3$ was $0.89 \pm 033 \mathrm{ng} / \mathrm{mL}$ as compared to $1.03 \pm 0.18 \mathrm{ng} / \mathrm{mL}$ in those with GOS $>3$ ( P value 0.1409) and $0.9 \pm 0.45 \mathrm{ng} / \mathrm{mL}$ in the group with FIM $\leq 4$ compared to $1.27 \pm 0.32 \mathrm{ng} / \mathrm{mL}$ in the group with FIM $>4$ (P value 0.0474).

Conclusions: We concluded that lower progesterone levels are associated with poorer outcome measures in male traumatic brain injury patients.

Keywords: Brain injury; Progesterone; Prognostic marker

Manuscript accepted for publication April 18, 2012

${ }^{a}$ Department Of Endocrinology And Metabolism, Gauhati Medical College and Hospital, Guwahati-32, India

${ }^{b}$ Corresponding author: Arundhati Dasgupta, Flat No 503, A-14, Games

Village, Borsajai, Guwahati -29, India.

Email: drarundhatidg@gmail.com

doi:10.4021/jnr101w

\section{Introduction}

Traumatic brain injury (TBI) is defined as damage to the brain resulting from external mechanical force, such as rapid acceleration or deceleration, impact, or penetration by a projectile [1]. Traumatic injury is a massive public health problem worldwide. TBI is a leading cause of mortality, morbidity, and socioeconomic losses in India. Conservative estimates from India indicate that nearly 1.6 million individuals will sustain TBI and seek hospital care annually [2].

TBI can cause a host of physical, cognitive, emotional, and behavioral effects, and the outcome can range from complete recovery to permanent disability or death. The damage following traumatic brain injury involves two processes - primary brain injury that occurs at the moment of trauma when tissues and blood vessels are stretched, compressed, and torn and secondary brain injury which involves a complex set of cellular processes and biochemical cascades that occur in the minutes to days following the trauma [3]. These processes include damage to the blood-brain barrier, release of factors that cause inflammation, free radical overload, excessive release of the neurotransmitter glutamate, influx of calcium and sodium ions into neurons, and dysfunction of mitochondria and can dramatically worsen the damage caused by primary injury [4]. Secondary brain injury accounts for the greatest number of TBI deaths occurring in hospitals [5].

The importance of progesterone as a promising neuroprotective agent has evolved over the last few years. Several animal studies indicate that administering progesterone after traumatic brain injury reduces neuronal loss, and improves functional outcomes. Human studies have also shown a favorable outcome with progesterone after brain injury [6]. Mechanisms of neuroprotection include decreased cerebral edema [7], decreased apoptosis [8], up-regulation of the inhibitory neurotransmitter GABA [9], antioxidant effects and reduction of inflammatory cytokines [10-12].

We sought to investigate whether lower levels of baseline serum progesterone can be used to predict worse outcome in moderate traumatic brain injury patients, as measured by Glasgow Outcome Scale (GOS) and Functional 
Independence Measure (FIM) score at 30 days postinjury.

To the best of our knowledge, no study has previously been conducted to determine the relationship between progesterone levels and prognosis of traumatic brain injury.

\section{Materials and Methods}

One hundred adult male patients of traumatic brain injury, who arrived within 10 hours of injury with a postresuscitation Glasgow Coma Scale score of 4 to 12 (as assessed by Emergency department personnel) were enrolled. To maintain homogeneity only patients who had intracerebral haemorrhage in CT scan brain were included.

Exclusion criteria included age less than 18 years or more than 60 years, index GCS score of less than 4 or greater than 12, indeterminate time of injury, penetrating brain injury, comorbid illness such as diabetes mellitus, hypertension, ischemic heart disease, or known cancer, extracranial visceral injury, associated acute or chronic spinal cord injury with neurologic deficits and where there was doubt whether the neurological status resulted from head trauma or acute or chronic spinal cord injury.

After head CT scanning, all such patients were treated in the ICU/ITU in order to maintain standard treatment for management of severe Traumatic brain injury (based on the guidelines of the American Association of Neurologic Surgeons).

Outcome was assessed at 30 days postinjury by a blinded outcome examiner according to two validated measuresthe Glasgow Outcome Scale (GOS) and Functional Independence Measure (FIM) score. Patients who were still hospitalized were evaluated in person while those who were discharged were assessed by telephone with the patient or the closest registered relative as per standard protocols. The patients were grouped into 2 categories: good outcome (GOS 4-5 and/or FIM5-7) and poor outcome (GOS 1-3 and/or FIM $1-4)$.

Serum for assessment of progesterone was collected and stored at $-20{ }^{\circ} \mathrm{C}$ on Day1. Progesterone was measured by radioimmunoassay (Diasorin 125I RIA KitStillwater, Minnesota 55082-0285, U.S.A). The normal reference value for males was taken as $0.60-2.11 \mathrm{ng} / \mathrm{mL}$.

\section{Scoring systems}

Brain injuries can be classified into mild, moderate, and severe categories based on Glasgow coma scale- A GCS of $\geq$ 13 or above is mild, $9-12$ is moderate, and 8 or below is severe [13].

The Glasgow Outcome Scale is a 5-point score given to victims of traumatic brain injury at some point in their recovery to categorize their outcomes. The five categories of the original scale are: dead, vegetative, severely disabled (the patient requires others for daily support), moderately disabled (the patient is independent but disabled), and good recovery.

The Functional Independence Measure (FIM) scale assesses physical and cognitive disability. The scale involves areas of self care, sphincter control, mobility, locomotion, communication, social adjustment/cooperation and cognition/problem solving and is scored from 1 to 7 based on level of independence: 7 Complete independence- Fully independent; 6 Modified independence -Requiring the use of a device but no physical help;5 Supervision -Requiring only standby assistance or verbal prompting or help with set-up; 4 Minimal assistance- Requiring incidental hands-on help only (subject performs $>75 \%$ of the task); 3 Moderate assistance -Subject still performs 50-75\% of the task; 2 Maximal assistance -Subject provides less than half of the effort (25-49\%); 1 Total assistance -Subject contributes $<25 \%$ of the effort or is unable to do the task.

Statistical analysis was done by applying $t$ test considering $\mathrm{P}<0.05$ to be significant.

\section{Results}

One hundred male patients fulfilling the inclusion criteria were screened between November 2010 to January 2011. Mean age was $35 \pm 11.4$ years, 77 were injured in a motor vehicle accident and 15 had a history of fall from height. Average time taken to reach the hospital was $3.14 \pm 1.8$ hours. Index GCS score was 4 to 8 in 84 patients and 9 to 12 in 16 patients.

Forty eight patients had a GOS score of $\leq 3$ and fifty two patients had a GOS score of $>3$ at one month post injury. The mean progesterone level in the group with GOS $\leq 3$ was $0.89 \pm 033 \mathrm{ng} / \mathrm{mL}$ and the mean progesterone level in the group with GOS $>3$ was $1.03 \pm 0.18 \mathrm{ng} / \mathrm{mL}$. The group with higher mean progesterone level at entry had better prognosis at one month of assessment though the result was not statistically significant ( $\mathrm{P}$ value 0.16 ).

Thirty six patients had an FIM score of $\leq 4$ and sixty four patients had an FIM score of $>4$ at one moth post injury. The mean progesterone level in the group with FIM $\leq$ 4was $0.9 \pm 0.45 \mathrm{ng} / \mathrm{mL}$ and the mean progesterone level in the group with FIM $>4$ was $1.27 \pm 0.32 \mathrm{ng} / \mathrm{mL}$. It was found that the difference of mean progesterone levels between both the groups was statistically significant $(\mathrm{P}$ value 0.048$)$ and those with a serum progesterone level $<1 \mathrm{ng} / \mathrm{mL}$ had a worse prognosis as indicated by a Functional Independence Measure (FIM) scale of $<4$ at one month post injury.

\section{Discussion}

There have been few studies to identify markers for prognos- 
tication of the patients' response to traumatic brain injury. SS Dhandapani et al found that unfavorable neurological outcome at 6 months was associated with $15 \%$ fall of serum albumin or low urinary creatinine at 3 weeks [14]. Hiroshi Takahashi et al identified fibrinolytic parameters, $\alpha_{2}$-plasmin inhibitor-plasmin complex (PIC) levels and D-dimer levels as admission prognostic markers of head injury in patients and found that higher levels predicted worse prognosis [15]. Other factors like circulating endothelial progenitor cells, S100B, neuron specific enolase have also been identified as predictors of severity and outcome of traumatic brain injury $[16,17]$. The present study shows that progesterone levels at admission is significantly related to prognosis of traumatic brain injury and lower levels may be used to predict worse prognosis .

Progesterone is a C-21 steroid hormone (molecular weight: 314.5 ) which is synthesized from cholesterol. Progesterone is present in the brains of men and women in small but roughly equal concentrations. Progesterone receptors are widely distributed throughout the central nervous system.

In the late 1980s, the importance of progesterone in brain injury was brought to light when Stein, while researching cerebral recovery after traumatic brain injury observed that female rats tended to recover better than males after an injury of identical severity. He hypothesized that sex-related differences in brain injury have a hormonal basis and that the magnitude of recovery depends at least in part, on where a female rat is in her estrus cycle at injury [18]. Subsequently, 65 animal studies conducted by 20 research groups working with 4 species (rats, cats, mice, and rabbits) have reported that progesterone exerts neuroprotective effects. Wright DW et al had demonstrated a strong inverse relationship between serum progesterone levels and cerebral edema in rats with bilateral medial frontal cortex injuries [19]. Progesterone reduces cerebral edema by stabilizing the bloodbrain barrier thereby preventing the indiscriminate flow of ions, water and other inflammatory molecules across the membrane [20], by modulating aquaporins that act as osmosensors and control water drainage into the ventricles of the brain [21] and by reducing the cytotoxic phase of edema caused by the accumulation of fluid inside neurons [22]. Roof RL et al found that postinjury blood brain barrier leakage was lower in progesterone treated than in the untreated group and attributed it to the antioxidant effects of progesterone [23]. Progesterone reduces lipid peroxidation and oxidative stress, by decreasing the generation of free radicals and enhancing endogenous free radical scavenging systems [24]. At the transcriptional level, progesterone reduces the nuclear concentration of $\mathrm{NF}$ KB implicated in the initiation of neuron inflammation and apoptosis after traumatic brain injury. Progesterone and its active metabolites are also potent antagonists of central nervous system inflammation after traumatic brain injury [24]. Progesterone also upregulates GABAa, an inhibitory neurotransmitter in the central nervous system and thereby decreases excessive injury-induced excitotoxicity caused by the release of glutamate or other excitatory neurotransmitters $[25,26]$.

Recently human studies have also established a beneficial role of progesterone in brain injury. Guomin Xiao et al found that there was a remarkably more favorable outcome among patients who were given progesterone compared with patients receiving placebo $(\mathrm{P}=0.034)$ at 3 months and 6 months postinjury [27].

We found that lower serum progesterone at baseline is associated with lower GOS score at 30 days. David W. Wright et al found that patients of traumatic brain injury who were treated with progesterone had a lower 30-day mortality rate and better Glasgow Outcome Scale-Extended and Disability Rating Scale scores than untreated controls [6].

We found that lower serum progesterone is significantly associated with lower FIM Score at 30 days. Jiang $\mathrm{N}$ et al had found that progesterone reduces cell damage and improves physiological and neurological function [28]. Roof $\mathrm{RL}$ et al had shown that progesterone improves cognitive recovery and decreases neuronal degeneration 21 days after traumatic brain injury [29].

This study provides a basis for conducting prospective studies in larger groups of subjects to determine the role of progesterone levels in predicting prognosis of traumatic brain injury.

\section{Conclusion}

In summary, we found that low progesterone levels were associated with poorer outcome measures in moderately severe traumatic brain injury in male patients. Our findings suggest potential applications of progesterone as an admission prognostic marker in male traumatic brain injury patients. The results of our study are encouraging and provide the necessary foundation for continuing the study with a larger subject population.

\section{Grant Support}

The authors have no financial or material support to declare.

\section{Conflicts of Interest}

The authors have no conflicts of interest to declare.

\section{References}

1. Maas AI, Stocchetti N, Bullock R. Moderate and severe traumatic brain injury in adults. Lancet Neurol. 
2008;7(8):728-741.

2. Gururaj G. Epidemiology of traumatic brain injuries: Indian scenario. Neurol Res. 2002;24(1):24-28.

3. Werner C, Engelhard K. Pathophysiology of traumatic brain injury. Br J Anaesth. 2007;99(1):4-9.

4. Park E, Bell JD, Baker AJ. Traumatic brain injury: can the consequences be stopped? CMAJ. 2008;178(9):11631170.

5. Ghajar J. Traumatic brain injury. Lancet. 2000;356(9233):923-929.

6. Wright DW, Kellermann AL, Hertzberg VS, Clark PL, Frankel M, Goldstein FC, Salomone JP, et al. ProTECT: a randomized clinical trial of progesterone for acute traumatic brain injury. Ann Emerg Med. 2007;49(4):391402, 402 e391-392.

7. Roof RL, Duvdevani R, Heyburn JW, Stein DG. Progesterone rapidly decreases brain edema: treatment delayed up to 24 hours is still effective. Exp Neurol. 1996;138(2):246-251.

8. Djebaili M, Guo Q, Pettus EH, Hoffman SW, Stein DG. The neurosteroids progesterone and allopregnanolone reduce cell death, gliosis, and functional deficits after traumatic brain injury in rats. J Neurotrauma. 2005;22(1):106-118.

9. al-Dahan MI, Thalmann RH. Progesterone regulates gamma-aminobutyric acid $\mathrm{B}(\mathrm{GABAB})$ receptors in the neocortex of female rats. Brain Res. 1996;727(1-2):4048.

10. Chao TC, Van Alten PJ, Walter RJ. Steroid sex hormones and macrophage function: modulation of reactive oxygen intermediates and nitrite release. Am J Reprod Immunol. 1994;32(1):43-52.

11. Drew PD, Chavis JA. Female sex steroids: effects upon microglial cell activation. J Neuroimmunol. 2000;111(12):77-85.

12. He J, Evans CO, Hoffman SW, Oyesiku NM, Stein DG. Progesterone and allopregnanolone reduce inflammatory cytokines after traumatic brain injury. Exp Neurol. 2004;189(2):404-412.

13. Parikh S, Koch M, Narayan RK. Traumatic brain injury. Int Anesthesiol Clin. 2007;45(3):119-135.

14. Dhandapani SS, Manju D, Vivekanandhan S, Agarwal M, Mahapatra AK. Prospective longitudinal study of biochemical changes in critically ill patients with severe traumatic brain injury:Factors associated and outcome at 6 months . IJNT.2010;7: 23-28.

15. Takahashi H, Urano T, Takada Y, Nagai N, Takada A. Fibrinolytic parameters as an admission prognostic marker of head injury in patients who talk and deteriorate. $\mathrm{J}$ Neurosurg. 1997;86(5):768-772.

16. Liu L, Wei H, Chen F, Wang J, Dong JF, Zhang J. Endothelial progenitor cells correlate with clinical outcome of traumatic brain injury. Crit Care Med. 2011;39(7):17601765.

17. Mehta SS. Biochemical serum markers in head injury: an emphasis on clinical utility. Clin Neurosurg. 2010;57:134-140.

18. Stein DG. Brain damage, sex hormones and recovery: a new role for progesterone and estrogen? Trends Neurosci. 2001;24(7):386-391.

19. Wright DW, Bauer ME, Hoffman SW, Stein DG. Serum progesterone levels correlate with decreased cerebral edema after traumatic brain injury in male rats. J Neurotrauma. 2001;18(9):901-909.

20. Duvdevani R, Roof RL, Fulop Z, Hoffman SW, Stein DG. Blood-brain barrier breakdown and edema formation following frontal cortical contusion: does hormonal status play a role? J Neurotrauma. 1995;12(1):65-75.

21. Amiry-Moghaddam M, Otsuka T, Hurn PD, Traystman RJ, Haug FM, Froehner SC, Adams ME, et al. An alpha-syntrophin-dependent pool of AQP4 in astroglial end-feet confers bidirectional water flow between blood and brain. Proc Natl Acad Sci U S A. 2003;100(4):21062111.

22. Roof RL, Duvdevani R, Stein DG. Progesterone treatment attenuates brain edema following contusion injury in male and female rats. Restor Neurol Neurosci. 1992;4(6):425-427.

23. Roof RL, Hoffman SW, Stein DG. Progesterone protects against lipid peroxidation following traumatic brain injury in rats. Mol Chem Neuropathol. 1997;31(1):1-11.

24. Stein DG, Wright DW, Kellermann AL. Does progesterone have neuroprotective properties? Ann Emerg Med. 2008;51(2):164-172.

25. Lambert JJ, Belelli D, Peden DR, Vardy AW, Peters JA. Neurosteroid modulation of GABAA receptors. Prog Neurobiol. 2003;71(1):67-80.

26. Brann DW, Zamorano PL, De Sevilla L, Mahesh VB. Expression of glutamate receptor subunits in the hypothalamus of the female rat during the afternoon of the proestrous luteinizing hormone surge and effects of antiprogestin treatment and aging. Neuroendocrinology. 2005;81(2):120-128.

27. Xiao G, Wei J, Yan W, Wang W, Lu Z. Improved outcomes from the administration of progesterone for patients with acute severe traumatic brain injury: a randomized controlled trial. Crit Care. 2008;12(2):R61.

28. Jiang N, Chopp M, Stein D, Feit H. Progesterone is neuroprotective after transient middle cerebral artery occlusion in male rats. Brain Res. 1996;735(1):101-107.

29. Roof RL, Duvdevani R, Braswell L, Stein DG. Progesterone facilitates cognitive recovery and reduces secondary neuronal loss caused by cortical contusion injury in male rats. Exp Neurol. 1994;129(1):64-69. 